\section{História e memórias do banco de leite humano do Instituto de Medicina Integral Prof. Fernando Figueira (1987-2009) em Recife, Pernambuco, Brasil}

\section{History and memories of the human milk bank of the Instituto de Medicina Integral Prof. Fernando Figueira (1987-2009) in Recife, Pernambuco, Brazil}

Karenina Elice Guimarães Carvalho 1 Maria Elizete Guimarães Carvalho 2 Sandra Hipólito Cavalcanti 3 Ednaldo Cavalcante de Araújo 4

\begin{abstract}
Objectives: to recount the history of the Instituto de Medicina Integral Professor Fernando Figueira (IMIP)'s Human Milk Bank (HMB), focusing on its pioneers and the introduction of the service.

Methods: a descriptive transversal study with historical focus based on the methods of oral history. The main materials used were bibliographical sources and direct structured interviews with seven participants. Content analysis revealed two categories: "the Creation of the IMIP's Human Milk Bank: its pioneers and their influences"; and "the Introduction of the Service".

Results: the IMIP's HMB, set up in 1987, was the brainchild of Professor Fernando Figueira and Dr. Vilneide Braga and its aim was to meet the needs of the Maternity hospital and its neonatal intensive care unit. The inauguration was attended by politicians, breastfeeding experts, TV celebrities and hospital staff.

Conclusions: the methods of oral history were used to build up a history of the origins and evolution of the IMIP's HMB based on the testimony of the individuals involved. The history of the IMIP's HMB is an ongoing, living process and force that produces change, dreams and hope and keeps alight the ideal of a better world for children, mothers and for society at large.
\end{abstract}

Key words Breast feeding, Milk banks, History

\footnotetext{
1,4 Departamento de Enfermagem. Centro de Ciências da Saúde. Universidade Federal de Pernambuco. Av. Prof. Moraes Rego, s.n. $2^{\circ}$ andar bloco A. Hospital das Clínicas. Cidade Universitária. Recife, PE, Brasil. CEP: 50.670-901.

E-mail:karenelice@yahoo.com.br

2 Centro de Educação. Universidade Federal da Paraíba. João Pessoa, PB, Brasil.

3 Banco de Leite Humano. Instituto de Medicina Integral Professor Fernando Figueira. Recife, PE, Brasil.
}

\section{Resumo}

Objetivos: reconstituir a história do Banco de Leite Humano (BLH) do Instituto de Medicina Integral Professor Fernando Figueira (IMIP), enfocando os idealizadores e a inauguração do serviço.

Métodos: estudo descritivo, transversal com enfoque histórico, orientado pela metodologia da história oral. Privilegiou-se a consulta a fontes bibliográficas e a entrevista direta a sete participantes, com roteiro estruturado. A análise das falas desvelou duas categorias: "Criação do banco de leite humano do IMIP: os idealizadores e suas influências"; e "A inauguração".

Resultados: o BLH do IMIP foi criado em 1987, com a idealização e o incentivo do Professor Fernando Figueira e da Dra. Vilneide Braga, e para suprir as necessidades da Maternidade e da unidade de terapia intensiva neonatal. Da inauguração, participaram autoridades politicas, autoridades em aleitamento materno, celebridades da mídia e profissionais do hospital.

Conclusões: o entrelaçamento entre história e memória, conduzido pelas trilhas da história oral, foi matriz para a construção da origem e evolução do BLH do IMIP, a partir da fala de sujeitos envolvidos nos fatos. A história do BLH do IMIP é um processo inacabado, vivo, é uma força geradora de transformação, sonhos e esperança, que mantém aceso o ideal de um mundo melhor para as crianças, para as mães e para a sociedade.

Palavras-chave Aleitamento materno, Bancos de leite, História 


\section{Introdução}

O declínio da prática do aleitamento materno no Brasil, é um evento notório principalmente após a industrialização e urbanização do país, fenômenos que se associam a saída da mulher para o mercado de trabalho, somando-se a elementos históricos, culturais, políticos, econômicos, e sociais. ${ }^{1-4}$ Esse evento também está associado à atuação dos pediatras, que orientavam até a década de 1980 a entrada precoce de outros alimentos na dieta da criança o que era também influenciado pela propaganda das indústrias de fórmulas infantis, havendo ainda a distribuição gratuita de leite pelos programas governamentais de suplementação alimentar.5,6 Outro fator agravante e complicador da situação constituíase na falta de apoio social e de cumprimento integral das leis trabalhistas.

É digno de nota também a participação da mídia na redução dos índices de aleitamento, pela propaganda de substitutos do leite materno, induzindo a modificação de hábitos populacionais. Esses fatores levaram a diminuição da prática do aleitamento materno no país que chegou a apresentar, na década de 1970, uma mediana de amamentação em torno de 2,5 meses. ${ }^{2}$ No entanto, com a evidência das doenças do desmame precoce, do aumento da mortalidade infantil e da desnutrição, em consonância com as baixas taxas de aleitamento materno, surgiram vários estudos que apresentavam os benefícios da amamentação para o binômio mãe-filho e também para a sociedade, dando início ao movimento mundial em favor da amamentação no final dos anos 1970 e início dos anos 1980, com a participação de órgãos como a Organização Mundial da Saúde (OMS), a Fundo das Nações Unidas para a Infância (UNICEF) e a Organização Panamericana de Saúde (OPAS). ${ }^{6}$

Houve, então, a necessidade de transformação nos vários determinantes que interferiam nessa prática: a comunidade, os profissionais e os serviços de saúde, e os meios de comunicação. O Brasil, corroborando iniciativas internacionais, elaborou políticas públicas e estratégias para manutenção do ato de amamentar, com o auxílio de instituições e profissionais de saúde, e de várias entidades e grupos de apoio.

O Instituto Nacional de Alimentação e Nutrição (INAN), autarquia vinculada ao Ministério da Saúde (MS), com apoio da OPAS e do UNICEF, criou, em 1981, o Programa Nacional de Incentivo ao Aleitamento Materno (PNIAM), órgão responsável pela coordenação das políticas em prol do aleitamento materno, desencadeando um movimento de valorização da prática da amamentação na sociedade brasileira. ${ }^{2,5}$

Uma das vertentes desenvolvidas pelo PNIAM foi a transformação da função dos bancos de leite humano e uma expansão do número de unidades, principalmente pela publicação da Portaria MS $n^{\circ}$ $322 / 88$ que aprovava as normas gerais, destinadas a regular a instalação e o funcionamento dos bancos de leite humano, no território nacional. ${ }^{7}$ Além da função de coletar e distribuir leite humano, estava a de direcionar esforços no combate ao desmame precoce, por intermédio principalmente do incentivo ao aleitamento materno e do treinamento e qualificação de profissionais. ${ }^{8}$ Neste contexto foi fundado o Banco de Leite Humano (BLH) do Instituto de Medicina Integral Prof. Fernando Figueira (IMIP) no ano de 1987, acompanhando o então processo de modificação.

O BLH do IMIP localiza-se próximo ao ambulatório do referido Instituto, ao lado do serviço de puericultura/vacina. Com ambiente físico para recepção; salas de atendimentos, higienização, coleta e o processamento do leite humano; e sala de reuniões. O BLH do IMIP atualmente realiza aproximadamente 4700 atendimentos, pasteurizando em torno de 250 litros de leite humano, por mês proviniente de 250 doadoras. Sua equipe é constituída por duas médicas, uma enfermeira, uma bióloga, quatro técnicas de enfermagem, um profissional administrativo e uma auxiliar de serviços gerais.

O propósito deste artigo é discutir a reconstituição histórica do banco de leite humano do IMIP, considerando as temáticas referentes aos idealizadores, bem como os fatores que influenciaram a criação do serviço e sua inauguração.

\section{Métodos}

Este é um estudo, tipo descritivo, transversal com enfoque histórico, utilizando entrevista a agentes sociais participantes da evolução do BLH do IMIP, bem como consulta a fontes bibliográficas. Os depoimentos foram colhidos seguindo um roteiro de entrevista estruturado com as seguintes questões norteadoras: Quais fatores determinaram a criação do BLH do IMIP? Qual era o seu local e a estrutura física? Como foi a inauguração e quem eram os profissionais na época da fundação? Quais as características da clientela atendida? Quais os pontos positivos e negativos dessa implantação?

Tomando-se a história oral como abordagem investigativa, a análise constituiu-se a partir da articulação entre os depoimentos colhidos e o referencial teórico estudado, relacionando-se e interpre- 
tando os acontecimentos e fatos históricos com os recortes das falas dos participantes, realizando um trabalho de localização e confronto das informações no tempo e no espaço, para compreender a criação do BLH. Encontraram-se, assim, dois núcleos temáticos: "Criação do banco de leite, os idealizadores e suas influências" e "A inauguração".

Realizou-se a pesquisa no próprio IMIP, no setor do banco de leite humano, sendo a coleta de dados executada no período de julho a outubro de 2009. Foram entrevistados profissionais atuantes e/ou que já atuaram no setor e também um representante da clientela. Esta amostra foi formada por sete sujeitos, sendo do tipo "por rede".9,10 Foi utilizado um aparelho de MP4 para o registro das falas.

Foram incluídas na pesquisa fontes orais de pessoas lúcidas que tiveram participação na criação e na evolução do banco de leite, no período de 1987 a 2009.

A pesquisa teve aprovação do Comitê de Ética e Pesquisa do IMIP, com o registro de $\mathrm{n}^{\circ} 14.120$, e posterior autorização dos participantes, mediante assinatura do Termo de Consentimento Livre e Esclarecido (TCLE). Antes da análise das entrevistas, os sujeitos leram as narrativas transcritas e nenhum apresentou contestações ou solicitou correções; depois, assinaram a carta de cessão sobre depoimentos orais, fornecendo assim autorização para uso e publicação dos relatos. Seguindo os princípios éticos, os depoentes não modificaram o texto e as falas foram utilizadas integralmente, sem receber ajustes de qualquer natureza.

\section{Resultados e Discussão}

\section{Criação do banco de leite humano do IMIP: os} idealizadores e sua influência

O banco de leite humano do IMIP surgiu no final da década de 1980, fazendo parte das iniciativas do PNIAM, o que pode ser confirmado pelo seguinte depoimento:

Foi o próprio Ministério da Saúde do Brasil que estava querendo expandir o número de banco de leite no Brasil, certo? E isso fez com que o IMIP, como já trabalhava aleitamento materno pelo Prof. Fernando Figueira, fosse uma das instituições que quiseram. Então, foi iniciativa do IMIP em procurar, não é? Mas era uma iniciativa do Ministério de expandir a rede de banco de leite. (Entrevistado 1)

Além das políticas de saúde da época, houve a participação do professor Fernando Figueira como idealizador e incentivador dessa criação, juntamente com a Dra. Vilneide Braga Serva. A Secretaria de Saúde do Estado de Pernambuco publicou em 1974 a Portaria $n^{\circ} 99$ de 03 de dezembro, que foi um instrumento a favor da amamentação, a qual já era levada o efeito na Instituição, contribuindo assim para a criação do BLH. ${ }^{11}$ Ainda, a importância da Dra. Vilneide no funcionamento do BLH do IMIP, foievidente ao mostrar interesse em coordenar um serviço no hospital que envolvesse o aleitamento, como observado no depoimento a seguir:

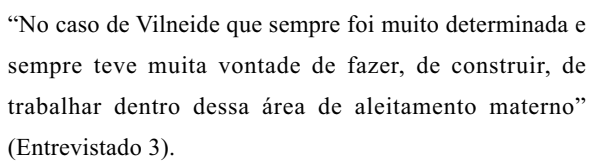

O BLH tinha a responsabilidade de promoção do aleitamento materno, além da execução das atividades de processamento do leite ordenhado. O serviço na instituição surgiu também para atender a estas exigências, uma vez que se edificaram a maternidade e a unidade de terapia intensiva neonatal (UTIN), em meados da década de 1980. Portanto, deveria suprir a clientela emergente de crianças prematuras que necessitavam das propriedades do leite humano, sendo ainda espaço destinado para ordenha, tratamento e distribuição do leite, e apoio para as mulheres com relação à amamentação, como posto no seguinte relato:

\footnotetext{
O que eu sentia é que tinha sido realmente uma necessidade do hospital pra atender a maternidade e a UTI neonatal pra atender os prematurozinhos do hospital. Havia era a necessidade da instituição, por conta do número de mães que precisavam ordenhar esse leite e ela precisava de um espaço pra ordenhar esse leite. (Entrevistado 3).
}

Percebe-se nas palavras das depoentes uma preocupação com o social. As mulheres que pariam bebês prematuros precisavam de espaço para ordenhar, de apoio e orientação para não perder o leite, tendo em vista sua utilização "mais adiante", quando seus filhos estivessem aptos a se alimentarem com leite materno.

Por outro lado é importante notar que o financiamento da implantação dos BLH no Brasil era feito com verbas federais e com a ajuda de alguns órgãos, como a Legião Brasileira de Assistência (LBA), o que se confirma pela seguinte fala:

"O banco de leite foi inaugurado, na época foi pela LBA, a LBA que dava assistência ao banco de leite, que a LBA 
é do governo, era do governo, não é?" (Entrevistado 4).

O PNIAM também tinha a proposta de transformar o aleitamento materno e levá-lo para todas as classes sociais, difundindo essa prática entre o povo. 12 Porém, mesmo sendo a criação do $\mathrm{BLH}$ instrumento dessa divulgação, ele não foi objeto de desejo da comunidade. Isto se observa no relato a seguir:

\footnotetext{
"Não. Eu realmente não posso fazer nenhuma associação entre banco de leite humano e questão do desejo da população em geral, não. Realmente eu não posso fazer essa ligação, não.” (Entrevistado 1).
}

As falas apresentadas e o contexto no qual se inserem ilustram que a criação do BLH do IMIP resultou de uma soma de fatores internos - vontade da própria instituição e de seus profissionais - e externos - reflexo das políticas brasileiras em prol do aleitamento materno - que financiaram a instalação de inúmeras unidades desse caráter no território nacional. Porém a ideia da necessidade do serviço realizado em tais unidades, naquela época, não era uma reivindicação da sociedade. Tal ausência de participação em fatos tão importantes para a vida social era comum naquele momento. A sociedade brasileira estava saindo de um regime não democrático, em que a reivindicação não se constituía uma prática. Não é de admirar pois que as futuras beneficiárias do serviço que se instalava não tivessem conhecimento do que estava acontecendo e portanto não lutassem por esse direito.

\section{A inauguração}

A inauguração do BLH do IMIP aconteceu no mês de abril de 1987, contando com a participação de autoridades políticas, autoridades em aleitamento materno, celebridades da mídia e profissionais do hospital, como referido nos relatos a seguir:

Quando inaugurou, aí foi toda aquela inauguração, né? Tava todos, A direção do hospital, [...] representantes do antigo Instituto Fernandes Figueira... Foi uma festa aqui, né? Aí estava quem: a esposa do presidente, a atriz que tava amamentando, na época, junto com algumas autoridades locais. E estávamos nós, né? O corpo de enfermagem. (Entrevistado 4).

Este depoimento é enfático em afirmar a grande festa que foi a inauguração do BLH do IMIP, com a presença da primeira dama do país da época, atrizes e personalidades importantes ligadas à área da saúde.
Era um momento em que se dizia "tudo é feito pelo social". Era um momento de nova república, de promessas de um Brasil melhor, de incentivo a políticas sociais, após muitos anos de restrições políticas aos cidadãos.

O PNIAM em sua vertente de esclarecimento do povo sobre $\mathrm{o}$ ato de amamentar, contava com o apoio de artistas e celebridades da mídia, influentes na população, o que justificava então a presença da chamada "musa do aleitamento materno" daquela época. Representava-se a mulher que amamentava, mesmo sendo bonita, ocupada, como um exemplo para todas as mulheres, que deveriam segui-la enquanto modelo.

Assim sobre o aleitamento materno na mídia, temos o depoimento abaixo:

\footnotetext{
A minha história aqui iniciou como mãe, né? como paciente aqui do IMIP. Através de uma entrevista na televisão, um anúncio, né? Eu achei interessante; naquele momento, eu estava amamentando e procurei algumas informações e quando eu cheguei aqui no IMIP eu recebi informações assim que me ajudavam muito, sabe? Que me ajudou a fazer o aleitamento exclusivo do meu filho. Eu já tava já perdendo o aleitamento, essa aproximação fez com que eu entendesse todo o processo e toda a importância que tem o aleitamento. Eu via muita revista, livros e tudo o que eu lia falava sobre o aleitamento materno, que o leite materno era o primeiro, principal leite pra criança. Então, eu não tinha a idéia do quanto seria assim, eu tinha a idéia do quanto era importante, mas eu não sabia como conduzir a situação. (Entrevistado 5).
}

A realização de propagandas nos meios de comunicação começou a despertar a atenção da população para o ato de amamentar, e a importância da alimentação infantil com o leite humano. Neste caso, a necessidade de se obter esclarecimentos acabou por atrair a população à instituição na procura pelo serviço. Tal serviço utilizava essa divulgação e oferecia uma linha telefônica para atender aos usuários, o que se confirma pelos depoimentos:

"É. A gente tinha uma linha telefônica, onde as pessoas ligavam". (Entrevistado 6). "Até quando eu liguei e disse: ' eu quero receber orientação'. Isso foi pelo telefone. E tinha a divulgação pela televisão". (Entrevistado 5).

Apesar de tudo, era patente o desconhecimento das pessoas sobre os acontecimentos. Daí porque não partiu da comunidade o desejo ou a reivindicação pela criação do BLH do IMIP. A população pouco sabia do que estava acontecendo no cenário da amamentação nacional e internacional. 


\section{Considerações finais}

A compreensão do entrelaçamento entre história e memória, conduzida pela história oral, foi matriz para a construção da origem e evolução do banco de leite humano do IMIP. Igualmente, a leitura e a reflexão sobre o referencial teórico que trata da temática, auxiliando a construção de uma história oral híbrida, onde fontes orais e escritas se confrontam e se articulam, contribuíram para a ressignificação da história e compreensão dos acontecimentos.

Diante do exposto, constatou-se que:

- O BLH do IMIP foi criado no ano de 1987, fazendo parte das iniciativas do PNIAM, contemplando a então proposta do programa - a de melhorar os índices de aleitamento materno no Brasil - pois era centro motivador da prática da amamentação e do tratamento dos problemas mamários, com atividades de processamento de leite humano;

\section{Referências}

1. Almeida JAG, Novak FR. Amamentação: um híbrido natureza-cultura. J Pediatr. 2004; 80: 119-25.

2. Venancio SI, Monteiro CA. A tendência da prática da amamentação no Brasil nas décadas de 70 e 80 . Rev Bras Epidemiol. 1998; 1: 40-49.

3. Alencar SMSM. Proteção legal ao aleitamento materno. In: Rego JD. Aleitamento materno: uma guia para pais e familiares. 2 ed. São Paulo: Atheneu; 2008. p. 261-81.

4. Góes GB, Rangel RO, Borges RLL. Nurse's educational practices from pospartum women on the breastfeeding. Rev Enferm UFPE on line. 2009; 3: 38-43.

5. Rea MF. Reflexões sobre a amamentação no Brasil: de como passamos a 10 meses de duração. Cad Saúde Pública. 2003; 19: 37-45.

6. Monteiro R. Norma brasileira de comercialização de alimentos para lactentes e crianças de primeira infância: histórico, limitações e perspectivas. Rev Panam Salud Pública. 2006; 19: 354-62.

7. Brasil. Portaria GM/MS no 322, de 26 de maio de 1988. Agência Nacional de Vigilância Sanitária. Brasília, DF. [acesso em 12 out. 2009]. Disponível em: http://elegis.anvisa.gov.br/leisref/public/showAct.php?mode= PRINT_VERSION \&id=18659

8. Maia PRS, Almeida JAG, Novak FR, Silva DA. Rede Nacional de Bancos de Leite Humano: gênese e
- Os principais sujeitos envolvidos no processo de implantação foram o Professor Fernando Figueira e a Dra. Vilneide Braga Serva, que possuíam vasto conhecimento em aleitamento materno;

- Eventos internos que fortaleceram os alicerces para a edificação do serviço foram a construção da maternidade e da UTI neonatal. O nascimento de crianças prematuras e sua assistência em unidade de cuidados intensivos necessitavam de um serviço para o processamento de leite humano ordenhado, essencial no tratamento e recuperação daquelas crianças. As mães também careciam de um lugar para a ordenha e apoio para resolver os possíveis problemas com a mama puerperal;

-A implantação do serviço de banco de leite não foi uma iniciativa por reivindicação da sociedade. A expansão e reconhecimento do serviço fora da instituição foram se revelando lentamente, utilizando inclusive os recursos da mídia falada e escrita para atingir a população.

evolução. Rev Bras Saúde Matern Infant. 2006; 6: 285-92.

9. Bom Meihy JCS. Manual de história oral. São Paulo: Loyola; 1996.

10. Carvalho MEG. Memórias da campanha de pé no chão: 1961-1644 (o testemunho dos participantes) [tese]. Natal: Universidade Federal do Rio Grande do Norte; 2000.

11. Pernambuco. Portaria $n^{\circ} 99$. Proíbe a propaganda realizada diretamente pelos fabricantes e distribuidores, através da doação do leite em pó às mães pobres nos hospitais e demais unidades da Secretaria de Saúde de Pernambuco. Diário Oficial da União [DOU], Brasília, DF, 3 dez 1974.

12. Araújo MFM. Situação e perspectivas do aleitamento materno no Brasil. In: Carvalho MR, Tamez RN. Amamentação: bases científicas. 2 ed. Rio de Janeiro: Guanabara Koogan; 2005. p. 269-81.

Recebido em 25 de agosto de 2010

Versão final apresentada em 13 de novembro de 2010

Aprovado em 1 de dezembro de 2010 